\title{
Bringing Order into Chaos \\ Building an Integrated School Management Information System - A Case Study from Germany
}

\author{
Angelina Lange and Andreas Breiter \\ Institute for Information Management, University of Bremen, Germany
}

\begin{abstract}
How can a public educational organization deal with new information requirements from outside the organization when there are problems with the internal data flows? The German school system is currently changing towards data-driven decision-making for school improvement and accountability. Data becomes an important asset and building large-scale information systems becomes a necessity. In other countries and especially in corporate organizations data warehouses have already been implemented to support analytical data processing for high-level decision-making. These existing approaches will be used to transfer some findings to the German education system. Based on the methodology of information needs analysis, we will introduce a case study from the German State of Bremen. Its department of education is under way of building an integrated school management information system. With the help of qualitative interviews and ethnographic methods, we elicited the requirements and suggested a step-by-step participatory design approach to combine information demand and supply.
\end{abstract}

Keywords: Integrated school management information system, case study, information needs analysis, interoperability, data warehousing, organizational problems

\section{BACKGROUND}

Throughout the last decade, the German school system has moved towards stronger accountability. In order to reach the goal of higher student outcomes, quantitative and qualitative measures of quality have been introduced. While other countries, especially the U.S. and the U.K., have a long tradition in using data, this is a fairly new field in Germany. Currently, the major trend moves towards State-wide standardized student achievement tests, often copied from large-scale assessments such as PISA, TIMSS or PIRLS. As the German school system is decentralized on the federal level to the 16 Laender (States) and centralized within the States, we can find 16 different set-ups of strategies and objectives for data use. As Visscher (2002) pointed out, there is a general distinction regarding the use of data: for

Please use the following format when citing this chapter:

Lange, A. and Breiter, A., 2009, in IFIP International Federation for Information Processing, Volume 292; Evolution of Information Technology in Educational Management; Eds. Tatnall, A., Visscher, A., Finegan, A., O’Mahony, C., (Boston: Springer), pp. 1-14. 
accountability or for school improvement. The current approaches in Germany have the claim for school improvement but are often used exclusively for accountability.

Both cases, the school system in general and building-level management in schools, have to deal with large amounts of data. This data can only be collected, processed and visualized with the help of information systems. Hence, most school districts and State Departments of Education are working on database systems to support the "thirst for data" by politicians, the general public as well as school administrators and education research. The existing information systems are isolated "island solutions", which have been developed internally to serve a single purpose in a specific situation. They are mostly incompatible, and this leads to heavy manual work with severe problems in data quality.

In this paper, we will introduce a case study from the small German State of Bremen (160 schools, 80,000 students), which is currently in the process of designing an integrated school management information system that should serve as the major data pool for all relevant decisions. As other countries and corporate organizations are far more advanced, we will take a look at some of the developments. Already in the beginning of the process, it became obvious that the major obstacles are not technical but organizational. Hence, the starting point was an in-depth information needs analysis with all stakeholders, which was compared to the data supply from the existing information systems. This gap analysis led to a specification of the data model and the definition of data exchange processes between different data owners and database systems. We will introduce the basic results of the information needs analysis and describe our step-by-step-solution.

\section{INTEGRATION OF INFORMATION SYSTEMS}

Based on Visscher's (2001, p. 4) original definition on school information systems, we have developed an extended version:

"Within an integrated school management information systems (ISMIS) the data from different school information systems and different scopes of the school management and administration are joined and prepared for the different stakeholders. The basis constitutes the administrative school information systems which include both the master data of schools, students, teachers and other aspects..." (Breiter et al. 2006, p. 5).

Even if there are still information systems for different purposes needed, e.g. management of assessment data and making them available for different stakeholders, an integrated school management information system seems to be needed (cf. figure 1). It allows the combination of information as it is more and more claimed by public, policy and media in the discussion of school quality. 


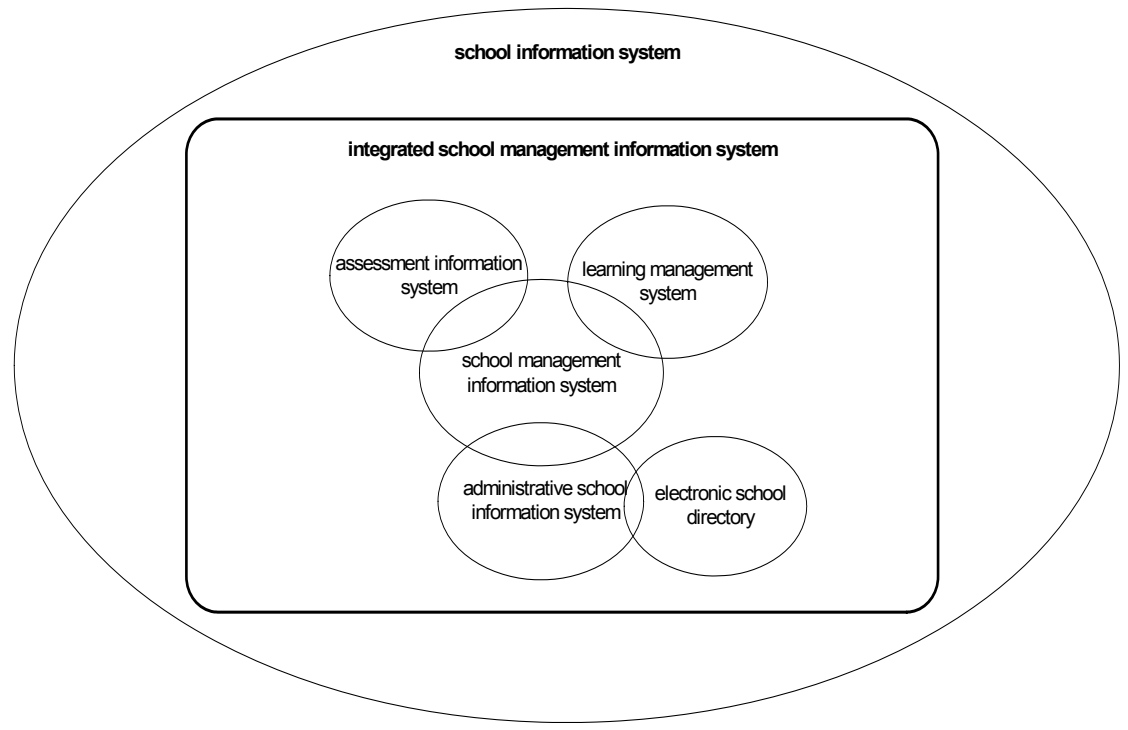

Figure 1: Typology of School Information Systems (Breiter et al. 2006, p. 6, fig.1)

Compared to other countries the history of school information systems in Germany is rather new. There is a body of empirical research on the use of school information systems in other countries, like the case study in New Zealand (Nolan, Brown, \& Graves, 2001), Visscher's and Bloemen's (1999) examination of data-systems in Dutch schools, an examination of experiences with a widely used school information system in the UK (Wild, Smith, \& Walker, 2001) and in Hong Kong (Fung \& Ledesma, 2001). Selwood (2008) has thoroughly analyzed the development of school information systems in the UK. He pointed out that they evolved from small-scale, self-tailored individual school-based systems to large-scale, commercial products, which resemble enterprise resource systems (ERP) in corporate organizations.

Since the 1980s, the integration of heterogeneous information systems became an important topic for many corporate organizations (e.g. Inmon 1996). Enterprise application integration (EAI) is translating data and functions from the format of one application into the format of another. It is a continual conversation between mutually incompatible systems. This is exactly the problem that many school districts are facing. Basically, there are three technical solutions for this problem:

(a) Building a completely new, all-in-one information system;

(b) Developing an intermediate system layer in which all data from the source systems is mirrored and later processed (data warehouse);

(c) Defining interfaces between all the different existing information systems to allow data exchange (interoperability framework).

The idea of the "perfect" information system, which includes all data, functionalities and organizational needs, is old. For some Ministries of 
Education it might make sense to start the use of information systems for some tasks totally new. Today there is more sensibility for the need of interoperability. But there is always the question of importing the "old" data into the new system or even let this be available in parallel. Additionally, it is expensive and interminable to plan and implement such an all-in-one system.

The idea of a data warehouse is to leave the operative systems as they are and just copy the important information for a central database. Here the data is consolidated and merged according to data type, general unit and others. The data is stored historically. This means that new data does not overwrite the old one. Especially for statistical purposes this is an important aspect. This idea of data management has already been an important topic in U.S. school districts, e.g. Spielvogel and Pasnik (1999) describe the development of a school data warehouse in Florida, Thorn and Mayer (2006) in a tri-state project.

Interoperability describes an approach to define interfaces between different information systems. Unlike the data warehousing approach, the idea is to make it possible to exchange data between different systems while in a data warehouse there is no connection between the systems. The European Interoperability Framework for e-government distinguishes between three different dimensions of interoperability (European Commission 2004): The basis is the technical interoperability, which defines the physical linkage. In the dimension of semantic interoperability, metadata is added, so a meaning for a specific context is created. On the third organizational dimension, coordination and reorganization of processes are addressed. This spans from the identification of all stakeholders, which are involved and the definition of roles and responsibilities to questions of legal compliance such as privacy and security. In a white paper with the title "Standards for Business", the European Standardization Institute (ETSI) introduces the layer of syntactic interoperability between the technical and the semantic one (Van der Veer \& Wiles 2006).

In other countries, there are projects to define the interoperability of school information systems. The School Interoperability Framework (SIF) in the U.S. and the sister project in the UK are both trying to set standards for data interchange between school information systems (http://uk.sifinfo.org). Due to the federal structure of the German education system, there is no comparable approach in sight. Some of the standards can be transferred while others need to be redefined. Up to now, there has been no real need to build integrated school information systems, as only few stakeholders were interested. This has dramatically changed due to the bad performance of German students in international assessment studies. 


\section{CASE STUDY: BREMEN STATE DEPARTMENT OF EDUCATION}

As there are no central responsibilities on education by the federal government in Germany, each of the 16 States is developing its own system. Some are more advanced than others. All systems are domain specific applications mostly addressing the administration of student and teacher records. They represent good solutions for the problems of communicating with schools about their personal resources and the students as well as creating statistics for different internal or external needs. The problem is that these systems are not integrated with other systems.

\subsection{Methodology}

In our methodology, we follow the information needs analysis as suggested by Winter \& Strauch $(2003,2004)$. This approach deals with the special issues of building a data warehouse. The way of building a data warehouse instead of building an all-in-one system was preferred because of financial considerations and the lack of software companies which can provide an integrated system. In Germany there is still no framework or definition of exchange formats in place so the third variant of interoperability with standardized data exchange was not really available for this case.

In the initialization (cf. box 1 in fig.2, next page), we identify key stakeholders as well as targeted decision-making processes. The second step is the analysis of the state-of-the-art (cf. box 2 in fig.2). Based on the knowledge about the organization and the state-of-the-art the next step is the information needs analysis (cf. box 3 in fig.2). Finally on the basis of the requirements a data model is created (cf. box 4 in fig.2). The information needs analysis and the data modelling are recursive and hence allow the adjustment of the system on changing general conditions.

\subsection{Context and Current Situation}

The Department for Education in Bremen has taken up the challenge to introduce an integrated school management information system (ISMIS). It is confronted with new internal and external requirements. Bremen has to deal with new data from the standardized tests to meet education policy goals. By moving towards school autonomy in recent years, the controlling mechanisms require data collection. Bremen has introduced a guideline for school quality to help schools in self-evaluation as well as with external inspectors. For the current legislative period the State of Bremen will publish its first "report on education". It should inform the parliament and the public about the performance and the challenges of the educational system and the individual school. 


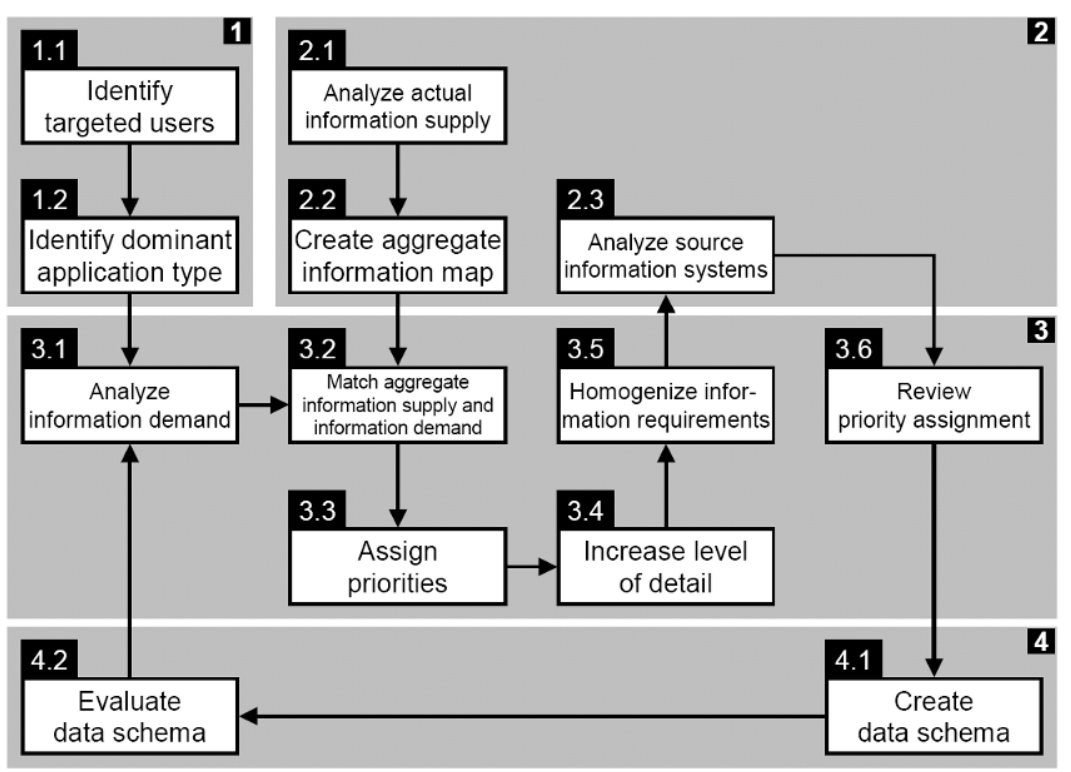

Figure 2: Activity Model for information needs analysis (Winter \& Strauch 2004, p. 1365)

External requirements are defined e.g. by national statistics, which are currently in a change process. The $\mathrm{KMK}^{1}$ has decided a new method to track every individual from kindergarten to adult education with the help of a unique student-ID. This development is highly disputed by privacy protection institutions and it would require a complete change of the information systems in each State (KMK 2006). A second external requirement is derived from the Bremen Freedom of Information Act, which regulates the rights of the citizens to access any (non-confidential) government information (see Kubicek 2006). School and student achievement data seems to be highly attractive.

\subsection{Initialization}

In our case study we are dealing with different stakeholders inside the school system especially inside the ministry of education. Beneath the needs of the highest level - the Minister for Education - there are different departments with special views on the subject. The following list gives an idea about the variety of information needs: 
- Statistics

- Human resources

- Facility management

- Transportation

- Curriculum

- Teacher training

- School improvement

- Inspections

- School supervisors for the different school types

- General education policies

- Professional development

- Quality management

With the help of an international workshop on school information systems (Breiter et al. 2008), the key stakeholders developed an initial idea about the relevant concepts and approaches from other countries.

\subsection{State-of-the-art}

By creating an inventory of documents and reports in use, we can achieve a first match between subjective information demands and information supply. This leads to an aggregated "information map", which is a model of the relevant information subjects on an aggregated level. This will serve as the basis for the analysis of all relevant data sources. This is a necessary condition to ensure a sufficient level of data quality. It is necessary to review the respective legal and regulatory framework and the "data culture" in the specific context (e.g. no public school ranking in Germany).

The as-is analysis of the existing database systems has uncovered a heterogeneous ICT infrastructure. The existing information systems were created from the different departments to solve current problems without taking into account requirements from other departments. The existence of several systems with intersecting content led to redundant data and communication problems between departments. Besides the central administrative system for students records, there are domain specific applications e.g. for finance, facility management or teacher records. This led to large problems with data quality. In the different systems for school management, the same teacher is connected with three different index keys, which makes data integration impossible. Apart from three major commercial information systems, there are a lot of individual workarounds in place. Even in the same department every employee has his/her own self-made "databases" for special purposes. A direct count came up with more than 1,000 different databases for 300 employees. This produces redundant and outdated data. Hence to be sure, data is collected again directly from schools, leading to confusion and additional workload. Additionally, there are old databases which are "retired with their administrator". It is often unclear if the 
information is available at all. As most information is individualized, work is done multiple times and redundant data is created.

Our research also shows that there is no real trust in the data which is in place. Most of the employees already had bad experiences working with wrong or outdated data. For this it is very important to only let data into the central system which is of high data quality. If there are bad experiences in the first time of using a new system or access to the data the trust and hope invested will be gone.

\subsection{Information needs analysis}

On the basis of individual and group interviews as well as participant observation during decision-making meetings, a basic understanding of the processes has been developed. We addressed this issue by splitting up the discussion into different levels. The general questions were discussed in groups with only one or two members (mostly the leaders) for every department. To get everybody with the process and to take into account their needs we additionally had individual interviews and group discussions within the departments. Information needs analysis addresses this challenge by trying to stimulate a negotiation process between different stakeholders (data managers, technology providers, decision-makers etc.). It tries to link those who are involved in producing information with the target audiences (users) who need - or are perceived to need - information to improve the quality of their decisions.

During the interviews and the group meetings, we found a large degree of misunderstanding about the use of data. The requirements of the two internal departments (Education \& General Services) are diverse and partly contradictory. One department's focus is on individual schools in their everyday work, the other one on aggregated data. So it was not only important to break down the ideas to the everyday work of the involved employees and avoiding technical terms but also introduce possibilities for the different departments to discuss with each other. By using concrete examples for the general concepts and visualizing every step of the process we reached a basis for finding a common understanding.

Another issue is that not everybody should be able to see, edit or even delete all data. There is some kind of fear to lose power if the data is no more secured by the person himself/herself but everybody can get it from the central system. It also might be that there is the idea to be controlled if everybody can see the results of the work. So a well defined identity management with specific roles and rights to see the data and to update it is not only important for security issues but also for organizational ones.

\subsection{Future system}

This step is about matching information supply and demand. It will end in a set of homogenized information requirements, defining information 
gaps. By identifying typical questions, which stakeholders have in mind when using imaginatively a "black box", we tried to get a first impression of information demands. As we know from prior research (Gorry \& Scott Morton 1989), decision-makers have difficulties in defining their needs. They tend to overestimate their needs or are not able to specify concrete data. We observed that not missing data was the primary problem for decision makers as nearly all information is available somewhere in the organization. Instead, it is important to identify the 'right questions'. After defining the goal it is necessary to assign priorities to the information requirements based on development costs, implementation time, data security and privacy, information granularity, refresh frequency and many more.

With the results of the first three phases (phase 4, data modeling is still ongoing) in mind, we defined a step-by-step-approach (see figure 3). The different requirements were assigned with priorities of creating a system which reduces the workload, increases data quality and reduces redundant data.

The core idea is to make data available which was so far individualized or only available to one department. Data which is relevant to others will be copied into a central database. First this database will be a central entrance to information, which will serve for building internal registers or information system for the public. Second the database will be extended with the functions for reporting.

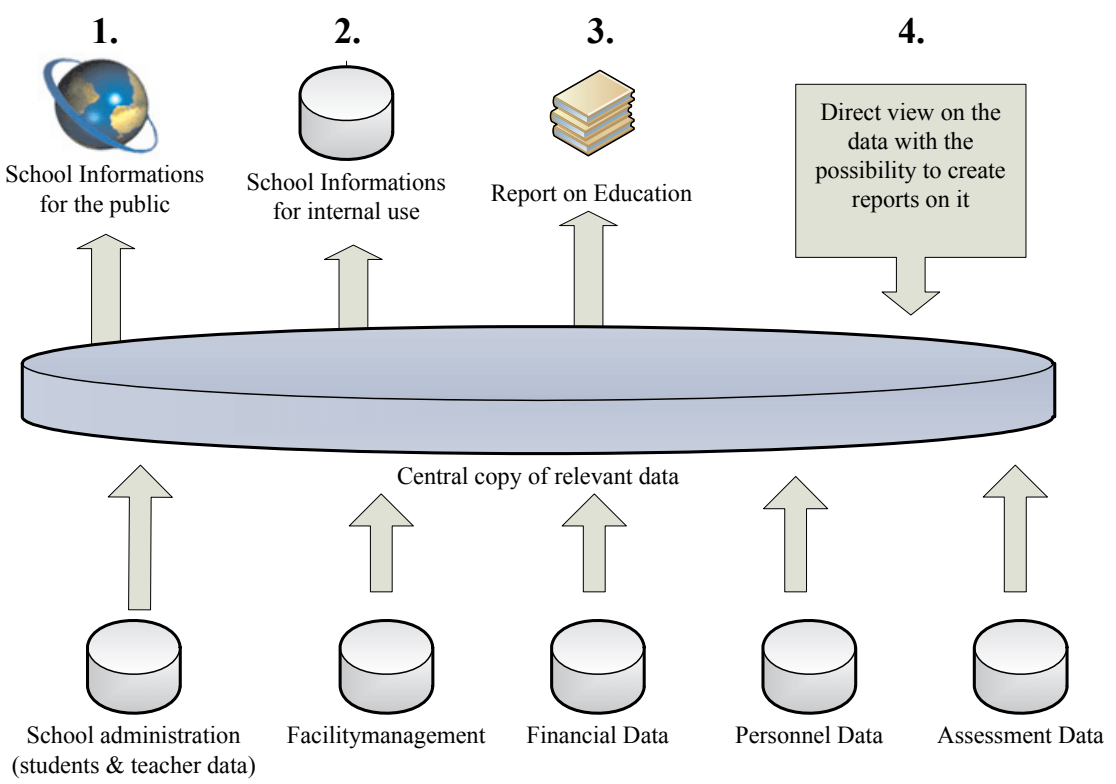

Figure 3: Architectural model of the integrated management information system 
Step 1: Automated processing of the public information system

The most pressing requirement was to provide basic data about individual schools to the public. As the quality of this data is crucial for any other information system, we put a lot of effort into the data flows and the ownership. We defined "godparenthoods" for specific data items. Individuals have the responsibility to update the information if it changes. They are reminded of this task by regular e-mails. The data is copied out of the source systems on a regular basis. Schools have the possibility to check and expand the information.

Step 2: Expanding public information about schools for internal uses

After creating a central storage for finding information about schools, this was expanded for internal use. As the employees in the departments for school supervision and inspections need more confidential details about the school additional data is copied regularly to the central database. In this step, there is also data introduced which is not directly connected to a specific school.

Step 3: Reorganizing responsibilities for data and implementing regular copies of the data into the data warehouse

This step is an ongoing task for the whole project. We address the core information of every department and, hence, the core power element. Analyzing the inter- and intra-departmental information flows is affecting the power balance within the organization what Crozier \& Friedberg (1977) called "micro-politics". Although human interaction is highly cooperative, competition is constantly in play. And the ownership of data is key. Data which is needed for others in their everyday work and often is asked for will also be part of the central database. This will be further extended to a data warehouse with analytical online data processing with current and historical data. By making more and more data centrally available, the creation of the "report of education" will be easier - at the same time - with better data. The data warehouse and the underlying processes will be constantly changing. Hence, organization and integration has to be checked regularly. The order in which the current databases and responsibilities are addressed and reorganized for central provision is an ongoing discussion in regularly interdepartmental meetings.

Step 4: Creating possibilities for data search and reports for decisionmaking

The information which was formerly available to individuals can now be accessed by all stakeholders in the organization. There is the need to define an identity management to clarify who can see, change and analyze which data. There will be the possibility to create individual reports. This is the future development for high-level decision makers.

\subsection{Findings}

As already introduced by Davis in 1982 there is a difference between the general information requirements of an organization and the specific 
information needs for a specific task. Addressing the issue of an integrated school information system we are facing the problem that these issues merge. This is already known from enterprises who try to build an ERP system. Information and knowledge became assets and therefore the management of these issues is a strategic and tactical task (Mentzas et al. 2003).There is a need for an overall information strategy. In our case we try to introduce two approaches of addressing this problem:

First we argue that information management is a task for the management. The implementation of a Chief Information Officer (CIO) might be a good idea. There is a need for a role which has an overview of all activities concerned with information management in the organization and has the freedom and power to make general decisions. As Rau (2004) puts it, the CIO is responsible for three areas and has to find a balance between them:

(a) costumer requirements/interaction with the users

(b) every-day-work (efficient and effective)

(c) strategic decision on information systems as selecting new technologies etc.

Philip (2007, p.253f.) describes the tasks as: "play the role of technology scout within the organization" and be the "technology interpreter" - fluent in two languages: the business language and the language of technology.

Second we give the advice to have an Information Audit in place. The strategic Information Audit tries to map and to analyze the relationship of information resources and organizational goals. Core of this is the identification of the organizations missions and goals as well as the role information and information systems play. These overall goals are broken down to specific and attainable short-term targets. Also the critical success factors (CSF) for the achievement of the objectives are addresses. The next step is to define activities which should ensure the meeting of the CSFs. At least the information resources, which are required for this are identified (Buchanan 1998). The like will be done for core processes, resources and content (Buchanan 2007). In table 1 you can see the general matrix which will be filled with the detailed results of the Information Audit.

Table 1: Information Audit Scope Matrix (Buchanan 2007, p.171, fig.8)

\begin{tabular}{|l|l|l|l|l|}
\hline & Management & Technology & Systems & Content \\
\hline Strategic & & & & \\
\hline Process & & & & \\
\hline Resource & & & & \\
\hline
\end{tabular}

\section{CONCLUSIONS}

Due to massive external pressure, the German education system is currently changing with high speed. The ultimate goal is to increase school 
quality. One major challenge is to collect the relevant data and to use it for system-level and building-level decision-making. Most States are building up large-scale databases in order to support this process. As we have pointed out, interoperability is in the first place an organizational rather than a technical challenge. Our case illustrated the problems of finding the same language to deal with the new situation and historically grown infrastructure. Information needs analysis is a highly interactive process which is necessary to define a priori the technical system requirements. In parallel, this leads to a common understanding of what should be done with data.

From our empirical findings, it became obvious, that education departments will need an overall information structure and to fill the position of a Chief Information Officer (CIO) at the top-level management. The more data becomes available, the more external pressure will force the education system to publish data and the more efficient and effective information management is necessary. Even with our approach of introducing a central database for reorganizing the information flow and building up a data warehouse there is the risk of information overload. Building an effective and efficient identity management will be a key future endeavour. Other countries are some steps ahead and Germany's school system should take the opportunity to learn.

\section{REFERENCES}

Breiter, A., Lange, A., \& Stauke, E. (2006). Introduction and Analytical Framework. In A. Breiter, E. Stauke, N. Büsching \& A. Lange (Eds.), Educational Management Information Systems - Case Studies from 8 Countries (pp. 5-16). Aachen: Shaker.

Breiter, A. et al. (2008). School information systems and data based decision making. Berlin et al.: Peter Lang.

Buchanan, S. \& F. Gibb (1998). "The information audit: An integrated strategic approach." International Journal of Information Management 18(1): 2947.

Buchanan, S., \& Gibb, F. (2007). The information audit: Role and scope. International Journal of Information Management, 27(3), 159-172.

Crozier, M., \& Friedberg, E. (1977). Actors and systems: the politics of collective action. Chicago: University of Chicago Press.

Davis, G. B. (1982). "Strategies for information requirements determination." IBM Systems Journal 21(1): 4-30.

European Commission (2004). European Interoperability Framework for Pan-european eGovernment Services. Luxembourg: European Communities.

Van der Veer, H. \& A. Wiles (2006). "Achieving Technical Interoperability - the ETSI Approach" ETSI White Paper No. 3, October 2006, European Telecommunications Standards Institute.

Fung, A. C. W. \& Ledesma, J. (2001). SAMS in Hong Kong Schools: A Centrally Developed SIS for Primary and Secondary Schools. In A. J. 
Visscher, P. Wild \& A. C. W. Fung (Eds.), Information Technology in Educational Management. Synthesis of Experience, Research and Future Perspectives on Computer-Assisted School Information Systems (pp. 3953). Heidelberg: Springer.

Gorry, G. A., \& Scott Morton, M. S. (1989). A Framework for Management Information Systems. Sloan Management Review.

Inmon, W. H. (1996). Building the Data Warehouse. New York, NY: John Wiley \& Sons.

KMK (2006). Zur langfristigen Sicherstellung der Datenbasis für die Bildungsberichterstattung. Frankfurt a.M.: Konsortium Bildungsberichterstattung.

Kubicek, H. (2006). Informationsfreiheitsgesetze vor einem weiteren Paradigmenwechsel. In D. Klumpp, $\mathrm{H}$.

Kubicek, H. \& R. Cimander (2007). Three dimensions of organizational interoperability. Online proceedings of the eGovInterop'07 Conference, Paris 2007.

Mentzas, G., D. Apostolou, et al. (2003). Process and Product Approaches in Knowledge Management. Knowledge Asset Management: Beyond the Process-centred Approaches. London, Springer: 1-18.

Nolan, C. J. P., Brown, M. A. \& Graves, B. (2001). MUSAC in New Zealand: From Grass Roots to System-Wide in a Decade. In A. J. Visscher, P. Wild \& A. C. W. Fung (Eds.), Information Technology in Educational Management. Synthesis of Experience, Research and Future Perspectives on Computer-Assisted School Information Systems (pp. 5575). Heidelberg: Springer.

Philip, G. (2007). "IS Strategic Planning for Operational Efficiency." Information Systems Management 24(3): 247-264.

Rau, K. G. (2004). "Effective Governance of IT: Design Objectives, Roles, and Relationships." Information Systems Management 21(4): 35-42.

Selwood, I. (2008). Managing with ICT in Education. In: Breiter, A., Lange, A., \& Stauke, E. (Eds.) School information systems and data based decision making (pp. 71-80). Berlin et al.: Peter Lang.

Spielvogel, B., \& Pasnik, S. (1999). From the School Room to the State House: Data Warehouse Solutions for Informed Decision-Making in Education. New York: EDC/Center for Children and Technology.

Thorn, C. A., \& Meyer, R. H. (2006). Longitudinal Data Systems to Support Data-Informed Decision Making: A Tri-State Partnership Between Michigan, Minnesota, and Wisconsin Madison, WI: Wisconsin Center for Education Research, University of Wisconsin.

Visscher, A. J. (2001). Computer-Assisted School Information Systems: The Concepts, Intended Benefits, And Stages of Development. In A. J. Visscher, P. Wild \& A. C. W. Fung (Eds.), Information Technology in Educational Management: Synthesis of Experience, Research and Future Perspectives on Computer-Assisted School Information Systems (pp. 318). Norwell, MA: Kluwer. 
Visscher, A. J. (2002). A Framework for Studying School Performance Feedback Systems. In A. J. Visscher \& R. Coe (Eds.), School Improvement Through Performance Feedback (pp. 41-72). Lisse: Swets \& Zeitlinger.

Visscher, A. J. \& Bloemen, P. P. M. (1999). Evaluation of the Use of Computer-Assisted Management Information Systems in Dutch Schools. Journal of Research on Computing in Education, 32(1), 172-188.

Wild, P., Smith, D. \& Walker, J. (2001). Has a Decade of Computerization Made a Difference in School Management. In C. J. P. Nolan, A. C. W. Fung \& M. A. Brown (Eds.), Pathways to Institutional Improvement with Information Technology in Educational Management. IFIP TC3/WG3.7 Fourth Working Conference on Information Technology in Educational Management, Auckland, NZ (pp. 99-120). Norwell, MA: Kluwer.

Winter, R., \& B. Strauch (2003). A Method for Demand-driven Information Requirements Analysis in Data Warehousing Projects. Journal of Data Warehousing, 8(1), 38-47.

Winter, R. \& B. Strauch (2004). Information requirements engineering for data warehouse systems. Proceedings of the 2004 ACM symposium on Applied computing. Nicosia, Cyprus, ACM: 1359-1365.s 